\title{
Functionalized Carbon Nanotubes with Gold Nanoparticles to Fabricate a Sensor for Hydrogen Peroxide Determination
}

\author{
HALIMEH RAJABZADE ${ }^{1}$, PARANDIS DANESHGAR*², ELHAM TAZIKEH ${ }^{3}$, AND \\ RAMIN ZAFAR MEHRABIAN ${ }^{3}$
}

${ }^{1}$ Department of Chemistry, Dezful Branch, Islamic Azad University, Dezful, Iran

${ }^{2}$ Faculty of New Science and Technology, University of Tehran, Tehran, Iran

${ }^{3}$ Department of Chemistry, Gorgan Branch, Islamic Azad University, Gorgan, Iran

p.daneshgar.chem@gmail.com

Received 25 October 2011; Accepted 29 December 2011

\begin{abstract}
A highly sensitive electrode was prepared based on gold nanoparticles/nanotubes/ionic liquid for measurement of Hydrogen peroxide. Gold nanoparticles of $20-25 \mathrm{~nm}$ were synthesized on a nanotube carbon paste electrode by cyclic voltammetry technique while the coverage was controlled by applied potential and time. The gold nanoparticles were modified to form a monolayer on CNT, followed by decoration with ionic liquid for determination of hydrogen peroxide. The experimental conditions, applied potential and $\mathrm{pH}$, for hydrogen peroxide monitoring were optimized, and hydrogen peroxide was determined amperometrically at $0.3 \mathrm{~V}$ vs. SCE at $\mathrm{pH}$ 7.0. Electrocatalytic effects of gold deposited CNT were observed with respect to unmodified one. The sensitivity obtained was 5 times higher for modified one. The presence of Au particles in the matrix of CNTs provides an environment for the enhanced electrocatalytic activities. The sensor has a high sensitivity, quickly response to $\mathrm{H}_{2} \mathrm{O}_{2}$ and good stability. The synergistic influence of MWNT, Au particles and IL contributes to the excellent performance for the sensor. The sensor responds to $\mathrm{H}_{2} \mathrm{O}_{2}$ in the linear range from $0.02 \mu \mathrm{M}$ to $0.3 \mathrm{mM}$. The detection limit was down to $0.4 \mu \mathrm{M}$ when the signal to noise ratio is 3 .
\end{abstract}

Keywords: Carbon nanotube; Gold nanoparticle; Ionic liquid, $\mathrm{H}_{2} \mathrm{O}_{2}$; Amperometric sensor.

\section{Introduction}

Since the discovery of the carbon nanotubes (CNTs) in 1991, there are tremendous interesting aspects on their characterization and potential application in various fields [1-9]. At the same time, due to a large specific surface area and good electronic properties, it can 
be used as a new support for catalysts [10,11]. Many attempts have been conducted to deposit various metal particles onto the surface of CNTs, some metals and their compounds, such as platinum, palladium, copper, nickel, ruthenium and so on, have been deposited on the CNTs successfully [12-16]. Chemical treatments are common methods to generate acid groups on CNTs. However, previous attempts to prepare metal nanoparticles on CNT surface have not often obtained size-similar and highly dispersed nanoparticles. One of the reasons is that metal nanoparticles are spontaneously formed at the defect sites on the surface of CNTs. Nanoparticles, especially the noble-metal nanoparticles, have attracted considerable attention in constructing electrochemical or optical sensors due to their small sizes and correspondingly unique electronic [17], optical [18], and catalytic properties [19]. Recently, electrochemical sensors based on nanomaterials such as gold [20], silver [17], platinum [21], copper [22], and metal oxide [23] have been widely used in environment, food and clinical fields owing to the inherent properties such as inexpensive, portable, high sensitivity, and high selectivity [24]. The use of ionic liquids that are solid at room temperature such as n-octyl-pyridinium hexafluorophosphate (nOPPF6) is shown to be advantageous in the fabrication of new form of biocomposite materials with attractive performance over other types of composites and pastes involving non-conductive binders. Carbon nanotubes (CNTs) based modified electrode exhibited excellent electron transfer capabilities for the oxidation of biomolecules [25-28]. CNTs could be combined with Au nanoparticles and the nanohybrids exhibited improved electro catalysis [29-32]. ILs possesses unique properties like wide potential windows, high thermal stability, viscosity, good conductivity and solubility. IL can be easily incorporated into carbon materials[33], chitosan [34], CNT [34].To the best of our knowledge, the combination of CNT-metal particle composite along with IL composite has not been explored as the matrix for the construction of a sensor for hydrogen peroxide determination. The modification condition in aqueous solution instead of organic anhydrous solution can much simplify the operating process, the electrostatic interaction between substrate and metal can make distribution better on the surface and electrochemistry is a powerful technique being both rapid and facile, and thus allowing to easily controlling the nucleation and growth of metal nanoparticles on the CNT substrate [35]. The electrocatalytic activity of an $\mathrm{Au} / \mathrm{MWNT} / \mathrm{OPPF} 6$ electrode for hydrogen peroxide oxidation was also investigated in detail in this work.

\section{Experimental}

\section{Materials and reagents}

Apparatus and electrodes voltammetric studies were performed in a three-electrode Teflon cell (volume of the solution employed $4 \mathrm{~mL}$ ). The cell was hooked up to a potentiostat system (Autolab, PGSTAT30/ GPES, Netherlands). A nanotube carbon paste electrode was used as the working electrode. A BAS MF $2030 \mathrm{Ag} / \mathrm{AgCl}$ reference electrode and a Pt wire counter electrode were also employed. Potential values are expressed against NHE in this study. The electroactive surface area of the CPE electrode was measured by the 
chronoamperometry in the deaerated $1 \mathrm{mM} \mathrm{Fe}(\mathrm{CN})_{6}$ in $\mathrm{KCl}(0.1 \mathrm{M})$ according to the Cottrell equation. The ionic liquid 1-n-octyl-pyridinium hexafluorophosphate was prepared according to a modified version of the procedure described by Safavi [36]. The AFM image of Au nanoparticle has been recorded.

\section{Pretreatment of carbon nanotubes}

\section{Electrode fabrication}

MWNTs were thiol (-SH) functionalized (MWNT(SH) using 4-aminothiophenol as the linker [37]. The required amount of the ionic liquid or mineral oil was mixed using pestle and mortar with the needed amount of above CNT for $30 \mathrm{~min}$. Although this IL is a solid powder, it has a sticky nature, and once it is mixed with graphite using pestle and mortar it tends to interact strongly and forms a very solid and mechanically stable composite. The surface of the composite can be polished very well and shows features similar to solid surfaces. Exactly $9.4 \mathrm{~mm}^{3}$ of the resulting paste was then packed firmly into the electrode cavity ( $2 \mathrm{~mm}$ diameter and $3 \mathrm{~mm}$ depth) of a glass sleeve. Electrical contact was established via a copper wire. The paste surface was smoothed on a weighing dish and rinsed carefully with double-distilled water prior to each measurement. The schematic of electrode preparation has been shown in figure 1 .

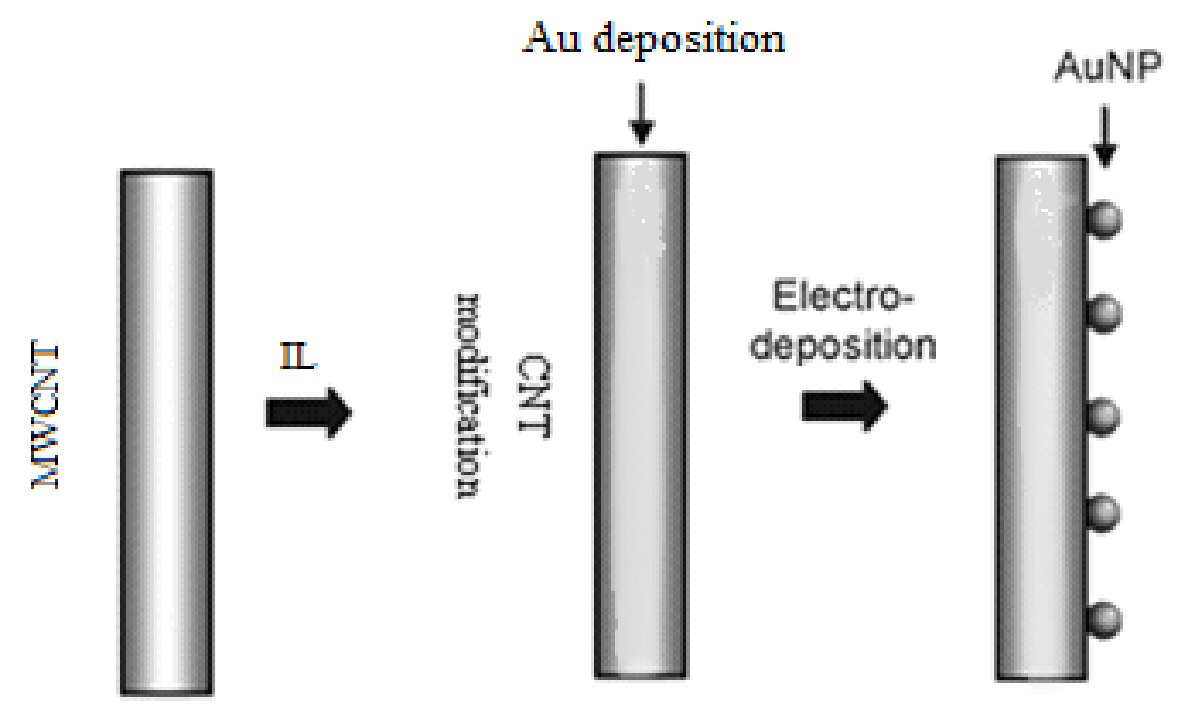

Figure 1. Schematic of MWCNT/Au/IL preparation.

\section{Preparation of Au nanoparticles on MWNT surface}

The electrochemical synthesis of Au nanoparticles on MWNT surface, has been done as 
regular electrochemical procedure which described by other researchers, briefly, Au particles were electrochemically deposited onto the CPE/MWNT/IL from a solution of $\mathrm{HAuCl}_{4}\left(5.5 \times 10^{-4} \mathrm{M}\right)$ by multiple cycling at the potential range of 1.10 and $0.0 \mathrm{~V}$ (vs. $\mathrm{Ag} / \mathrm{AgCl}$ as reference electrode) with a scan rate of $100 \mathrm{mV} / \mathrm{s}$. The modified electrodes were washed thoroughly with $\mathrm{PB}$ solution $(\mathrm{pH} 7.0)$ and stored at $4{ }^{\circ} \mathrm{C}$. The AFM image of the nano-structure has been shown in figure 2 .

\section{Result and Discussion}

\section{Electrochemical properties of Au/MWNT composites}

Electrochemical performances of the electrodes, MWNT(SH) (bare), MWNT(SH)-Au, MWNT (SH)-Au/ IL , were investigated using $\mathrm{Fe}(\mathrm{CN}) 6^{3-/ 4-}$ system as a redox marker (Fig.3). Well defined redox characteristics of $\mathrm{Fe}(\mathrm{CN}) 6^{3-/ 4-}$ were observed for all the modified electrodes but with variations in the values of difference between the anodic and cathodic peaks (Ep). CV of $\mathrm{Fe}(\mathrm{CN})_{6}{ }^{3-/ 4-}$ redox probe at MWCNT(SH) (bare) exhibits peaks with $\triangle \mathrm{Ep}$ as $\sim 50 \mathrm{mV}$. Presence of $\mathrm{Au}^{0}$ on the surface of MWNT caused an increased electrocatalytic activity. Also, peak current noticed at MWNT(SH)-Au/IL is much higher than the bare electrode. CVs of MWNT(SH)-Au/IL and MWNT(SH) electrodes were recorded at different scan rates in $1 \mathrm{mM}[\mathrm{Fe}(\mathrm{CN}) 6]^{3-/ 4-}(\mathrm{pH} 7.0)$. The anodic and cathodic peak current values increased linearly with scan rates in the range of $10-100 \mathrm{mV} / \mathrm{s}$. This infers that the electron transfer at these electrodes is a surface confined process. $\Delta E \mathrm{p}$ is lower for MWNT(SH) electrode as compared to MWNT(SH)-Au/IL. The existence of IL and $\mathrm{Au}$ provides a favorable potential window and electrocatalytic behavior for the hydrogen peroxide electron transfer to the electrode.
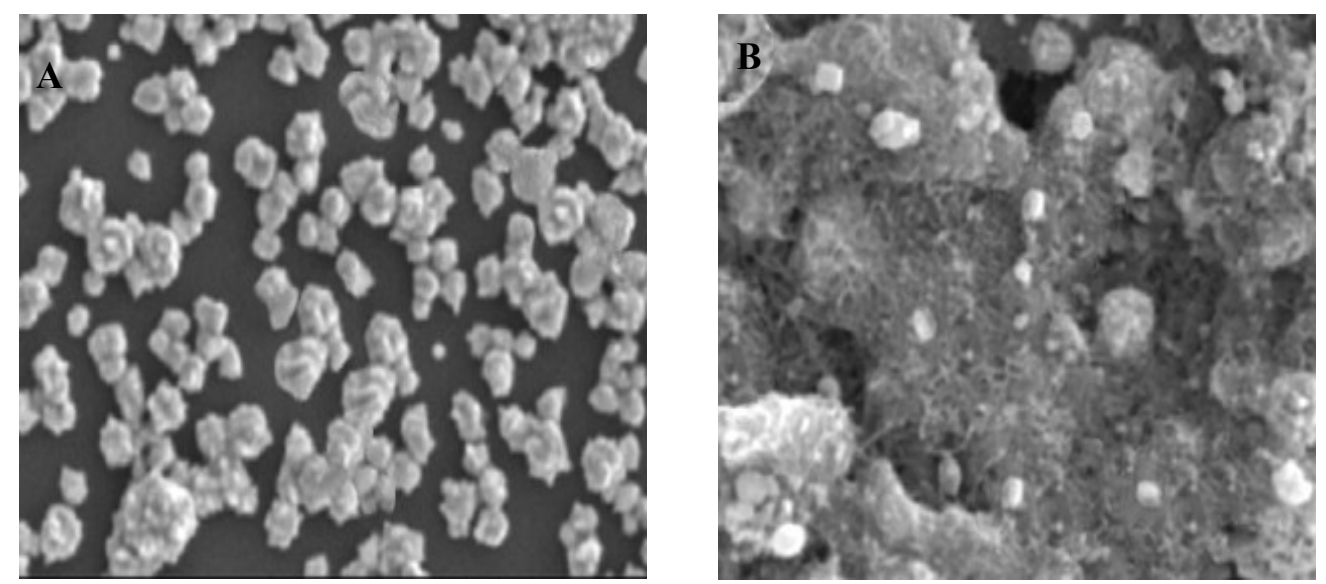

Figure 2. SEM images of MWNT(SH)-Au (a) and (b) MWNT(SH)-Au/IL. 


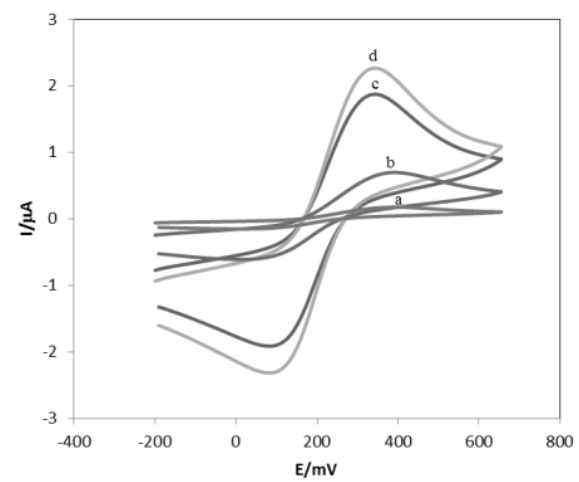

Figure 3. Cyclic voltammograms of different modified electrodes: a) MWCNT b) MWCNT(SH), c)MWCNT(SH)Au and d)MWCNT(SH)Au/IL. Supporting electrolyte=0.1M $\mathrm{KCl}$ containing $1 \mathrm{mM}$ of $(\mathrm{FeCN})_{6}^{-3 / 4}$; scan rate $=80 \mathrm{mV} / \mathrm{s}$.

\section{Optimization of the IL-carbon composite ratio}

The attractive behavior of the new ionic liquid (n-octylpyridinium PF6) towards the fabrication of ionic liquid/Carbon type biocomposite electrodes has been illustrated. This was made in connection to amperometric detection of the liberated hydrogen peroxide in comparison to a MWCN-based mineral oil electrode with a similar loading. Initial experiments aimed at the optimization of the ionic liquid loadings using ferricyanide as a probe. Fig. 4 displays the effect of different ionic liquid loadings upon cyclic voltammograms in a phosphate buffer solution (A), and in a $4 \mathrm{mM}$ ferricyanide solution (B). Ten percent loading of the ionic liquid shows very large background current. An increase in background current upon repetitive cycling (data not shown) was also observed at this loading indicating low stability of this composition. On increasing the loading from $10 \%$ to $50 \%$, a dramatic decrease in background current was observed along with improved stability upon repetitive cycling.

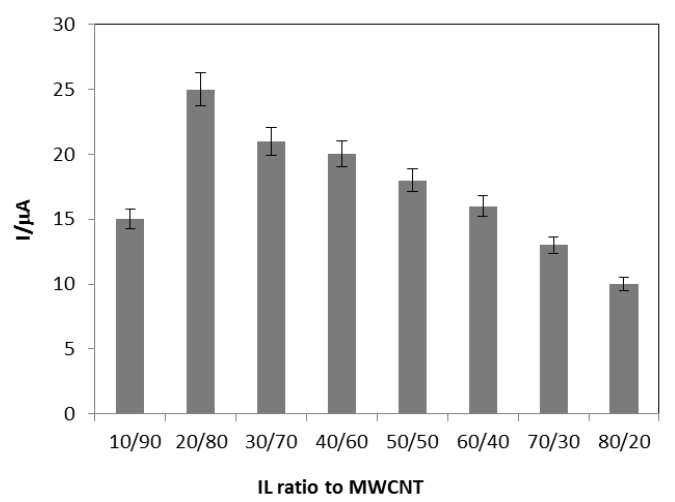

Figure 4. The current comparsion obtained from the cyclic voltammograms for phosphate buffer $0.05 \mathrm{M} \mathrm{pH7.0}$ and $4 \mathrm{mM}$ of $\mathrm{Fe}(\mathrm{CN})_{6}^{-3 / 4}$ using IL/MWCNT paste electrode in different ratio. Scan rate of voltammogram for this diagram was $50 \mathrm{mV} / \mathrm{s}$. 
The composites with loadings less than $40 \%$ were highly unstable in solution and were showing slow increase in background current while in solution. That is why there is a slight difference in background current between blank phosphate buffer and ferricyanice solutions, since in most experiments, the sequence of experiments was first single blank measurement followed by $\mathrm{CV}$ in ferricyanide, and finally capacitance measurement in blank phosphate buffer. Loadings of $50 \%$ and higher showed nearly the same low background currents and stability. Low loadings show larger background currents with larger peak-to-peak separations as shown for $20 \%$, and $40 \%$ loadings. On increasing the loading to $60 \%$, and $80 \%$ ionic liquid resulted in a significant decrease in the background currents. As the loading of IL increases, it leads to a better filling between the MWCNT particles and hence higher mechanical stability. This further leads to lower background currents since less water will be penetrating through the composite. As the background current decreases, the analytical current to background ratio increases. A voltammetric comparsion has been taken for the 50\% n-octylpyridinium IL were compared with another ionic liquid (1-butyl-3methylimmidazolium hexafluorophosphate) that is liquid at room temperature and the result shows the selected IL is more suitable by presenting high current and lower redox potential. The peak-to-peak separation followed a similar decreasing trend up to $70 \%$, but started to increase afterwards as can be clearly seen for the $80 \%$ loading. Further optimization of the composition was performed by measurement of capacitance, resistance, cathodic currents, and peak-to-peak separation using cyclic voltammograms for $5 \mathrm{mM}$ ferricyanide. The capacitance of the IL-based electrode decreases greatly above $20 \%$ and levels off at $50 \%$. This behavior contradicts that for carbon paste electrodes utilizing ionic liquids that are liquid at room temperature such as 1-butyl- 3-methylimmidazolium hexafluorophosphate where the capacitance of the IL carbon paste electrode jumps greatly above $40 \%$ and levels off at $50 \%$. The exact reason for this is not fully understood. Loadings of ILs above $50 \%$ show dramatic increase in resistance, but this is much lower than that for the mineral oil based electrodes. After optimizing the electrode and condition the cyclic voltammogram of $\mathrm{H}_{2} \mathrm{O}_{2}$ at different concentration has been recorded which is shown in figure 5 .

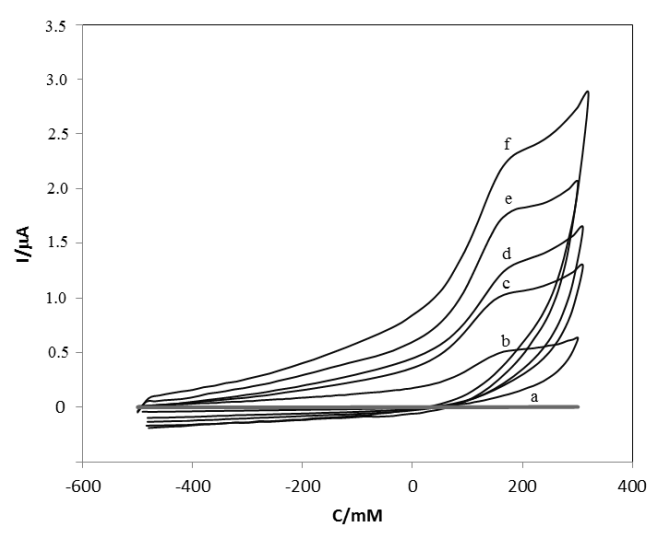

Figure 5. Cyclic voltammogram of $\mathrm{H}_{2} \mathrm{O}_{2}$ at different concentration, in phosphate buffer $0.05 \mathrm{M} \mathrm{pH} 7.0$ and scan rate $50 \mathrm{mV} / \mathrm{s}$. Concentration of $\mathrm{H}_{2} \mathrm{O}_{2}$ are a) 0, b) 0.05 , c) 0.1 , d) 0.15 , e) 0.2, f) 0.3 respectively. 


\section{Amperometric response}

Fig. 6 displays the amperometric response of MWNT(SH)Au/IL biosensor for the successive step changes of hydrogen peroxide concentrations in PBS (pH 7.0) at an operating potential of $0.3 \mathrm{~V}$. For a comparative purpose, the current-time curve at the MWNT(SH) electrode was recorded (Fig. 6, curve b). At the MWNT(SH)-Au/IL electrode, a small current response was noticed as compared to $\mathrm{MWNT}(\mathrm{SH})$. This clearly This clearly demonstrates the importance of the presence of IL over the surface of MWNT(SH) on augmenting the current response to hydrogen peroxide. MWNT(SH)-Au/IL sensor exhibited a linear response to hydrogen peroxide in the concentration range of $0.02-0.3 \mathrm{mM}$ with a correlation coefficient of 0.9981 . The sensitivity of MWNT(SH)-Au/IL sensor was $110 \mu \mathrm{AM} \_1$ as

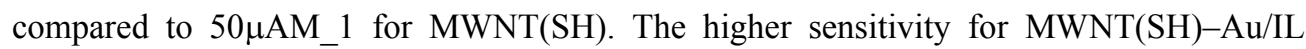
electrode documents the importance of the modification of electrode by gold nano particles.

\section{Reproducibility and stability of the $\mathrm{H}_{2} \mathrm{O}_{2}$ sensor}

The repeatability of the current response of the IL/Au/MWCNT electrode was examined at an $\mathrm{H}_{2} \mathrm{O}_{2}$ concentration of $0.5 \mathrm{mM}$. The relative standard deviation was $2.9 \%$ for ten successive assays, showing a fairly good repeatability. The electrode-to-electrode reproducibility of six sensors, prepared under the same conditions independently, shows a good reproducibility with a relative standard deviation of $4.4 \%$. The IL/Au/MWCNT electrode was dry stored at $4^{0} \mathrm{C}$ when it was not in use. The sensor retained $95 \%$ of its initial current response after 25 day storage. The sensor did not lose its sensitivity in the period of the storage. Therefore, the IL/Au/MWCNT composite is an efficient matrix to retain activity. The excellent stability of the sensor can be attributed to three points as follows. For the existence of IL, improved better potential range and help to get better electrocatalytic property of paste which has been deposited by Au nano-pa rticles.
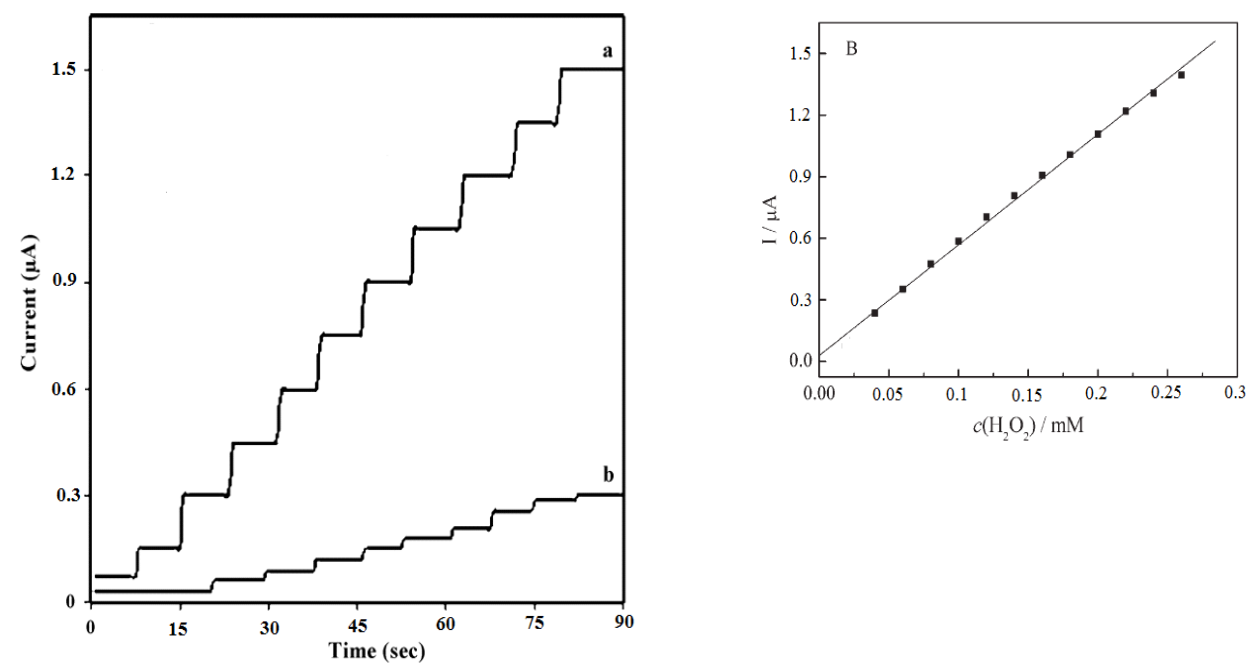

Figure 6. A) Chronoamperometric current response of electrode a)MWCNT(SH)Au/IL and b)MWCNT(SH) for successive addition of $0.05 \mathrm{mM} \mathrm{H}_{2} \mathrm{O}_{2}(0.02-0.3)$ Applied potential, 0.3 $\mathrm{mV}$ (vs. $\mathrm{Ag} / \mathrm{AgCl}) . \mathrm{B}$ ) the calibration curve obtained from Fig6A. 


\section{Interference study}

The influence of chemical interferences was also evaluated in the PBS (pH 7.0) containing $0.02 \mathrm{mM} \mathrm{H}_{2} \mathrm{O}_{2}$ in the presence of ethanol, glucose, sucrose, oxalic acid, uric acid and ascorbic acid with the same concentration. It was found that ethanol, glucose, sucrose, oxalic acid and uric acid didn't cause any interference in the design concentration of $\mathrm{H}_{2} \mathrm{O}_{2}$. Ascorbic acid showed a slightly interference. The results were similar to those reported before.

\section{Recovery}

The recovery tests of hydrogen peroxide ranging from $3.0 \times 10^{-7}-2.0 \times 10^{-4} \mathrm{M}$ were performed. The results are listed in Table 1. The recoveries varied on the range from 96.6 to $103.3 \%$ and the R.S.D. was $3.2 \%$.

Table1. The recoveries of peroxide hydrogen using present method.

\begin{tabular}{l|l|l}
\hline Added $\left(\mathrm{mol} \mathrm{L}^{-1}\right)$ & Found $\left(\mathrm{mol} \mathrm{L}^{-1}\right)$ & Recovery\% \\
\hline $3.0 \times 10^{-7}$ & $2.90 \times 10^{-7}$ & 96.6 \\
$5.0 \times 10^{-6}$ & $5.15 \times 10^{-6}$ & 103 \\
$2.0 \times 10^{-6}$ & $2.05 \times 10^{-6}$ & 102.5 \\
$5.0 \times 10^{-6}$ & $4.92 \times 10^{-6}$ & 98.5 \\
$3.0 \times 10^{-5}$ & $3.1 \times 10^{-6}$ & 103.3 \\
$5.0 \times 10^{-5}$ & $5.06 \times 10^{-6}$ & 101.2 \\
$2.0 \times 10^{-4}$ & $1.96 \times 10^{-6}$ & 98 \\
\hline
\end{tabular}

\section{Conclusion}

In the present work, Au nanoparticles were electro-crystallized on MWNTs by a potentialstep method and then covered by ionic liquid. The size range of these particles was about 20-25 nm. Additionally, Au/MWNT composites exhibit a high catalytic activity for the oxidation of hydrogen peroxide. The application of carbon nanotubes functionalized with metal, also alloy, metal oxide, compound semiconductor, and other nanoparticles is likely to expand greatly in the future. The reliability and stability of the CPE modified by Au NPs offered a good possibility for extending the technique in analysis.

\section{Acknowledgment}

The authors express their appreciation to the Research Council of the University of Tehran and Research Council of the Islamic Azad University of Dezfool for the financial support of this work. 


\section{References}

1. $\quad$ Iijima S Nature, 1991, 354, 56.

2. Wong E W, Sheehan P E and Lieber C M, Science, 1997, 277, 1971.

3. Mintmire J W and White C T, Carbon, 1995, 33, 893.

4. Berber S, Kwon, Y K, Tomanek D, Phys. Rev. Lett. 2000, 84, 4613.

5. Zhang B, Liang J, Xu C L, Wei B Q, Ruan D B and Wu D H, Mater. Lett. 2001, 51, 539.

6. Dillon A C, Jones K M, Bekkedahl T A, Kiang C H, Bethune D S and Heben M J, Nature, 1997,386, 377.

7. Liu C, Fan Y Y, Liu M, Cong H T, Cheng H M and Dressel-haus M S, Science, 1999,286, 1127.

8. Li X S, Zhu H W, Ci L J, Xu C L, Mao Z Q, Wei B Q, Liang J and Wu D H, Carbon, 2001, 39, 2077.

9. Fan S S, Chapline M G, Franklin N R, Tombler T W, Cassell A M and Dai H J, Science, 1999, 283, 512.

10. Ang L M, Hor T S A, Xu G Q, Tung C H, Zhao S P and Wang J L S, Carbon, 2000, 38, 363.

11. Che G L, Lakshmi B B, Fisher E R and Martin C R, Nature, 1998, 393, 346.

12. Xu C L, Chen J F, Cui Y, Han, Q Y, Choo H, Liaw, P K and Wu D H, Adv. Eng. Mater. 2006, 8, 73.

13. Chen J F, Xu C L, Mao Z Q, Chen G R, Wei B. Q, Liang J and Wu D H, Sci. Chin. $A, 2002,45,82$.

14. Chen G R, Xu C L, Mao Z Q, Li Y B, Zhu J, Ci L J, Wei B Q, Liang J, Wu D H, Chin. Sci. Bull. 2000, 45,134.

15. Khare R and Bose S, J. Minerals \& Materials Charact. \& Eng., 2005, 4, 31.

16. Xu S X, Li F Y, Wei R Z, Carbon, 2005, 43, 861.

17. Rena X L, Menga, X W, Chena D, Tanga F, Jiao J, Biosens. Bioelectron. 2005, 21, 433.

18. Zheng J W, Li X W, Gu R, Lu T H, J. Phys. Chem. B, 2002,106, 1019.

19. Yantasee W, Deibler L A, Fryxell G.E, Timchalk C, Lin Y H, Electrochem. Commun. 2005, 7, 1170.

20. Weng J, Xue, J M, Wang J, Ye J S, Cui H F, Sheu F S and Zhang Q Q, $A d v$. Funct. Mater. 2005, 15, 639.

21. You T Y, Niwa O, Tomita M, Hirono S, Anal. Chem. 2003,75, 2080.

22. Wang H Y, Huang Y G, Tan Z A, Hu X Y, Anal. Chim. Acta, 2004, 526, 13.

23. Liu G D and Lin Y H, Anal. Chem. 2005, 77, 5894.

24. Wang J. Analyst, 2005, 130, 421.

25. Y Zou, Xiang C, Sun L X and Xu F, Biosens. Bioelectron. 2008, 23, 1010.

26. Shobha D R, Sriman Narayanan S. Biosens. Bioelectron. 2008, 23, 1404.

27. Vasilis G G, Law S A, Ball J C, Andrews R, Bachas L G, Anal. Biochem. 2004,329, 247.

28. Deng C, Chen J, Chen X, Xiao C, Nie L, Yao S, Biosens. Bioelectron. 2008, 23, 1272. 
29. Gopalan A I, Lee K P, Manesh K M, Santhosh P, Kim J H, Kang J S, Talanta, 2007,71, 1774.

30. Miguel A C, Luis M L, J. Mater. Chem. 2006, 16, 22.

31. Chen S, Yuan R, Chai Y, Zhang L, Wang N and Li X, Biosens. Bioelectron. 2007, 22,1268.

32. Choi H C, Shim M, Bangsaruntip S, Dai H, J. Am. Chem. Soc. 2002, 124, 9058.

33. Zhang Y, Zheng J, Electrochem Commun. 2008,10, 1400.

34. Xi F, Liu L, Wu Q and Lin X, Biosens. Bioelectron. 2008, 24, 29.

35. Gao G, Guo D, Wang C and Li H, Electrochem. Comm. 2007,9, 1582.

36. Maleki N, Safavi A, Tajabadi F, Anal. Chem. 2006, 78, 3820.

37. Santhosh P, Gopalan A and Lee K P, J. Catalysis, 2006, 238, 177. 


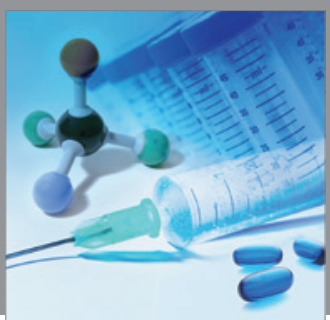

International Journal of

Medicinal Chemistry

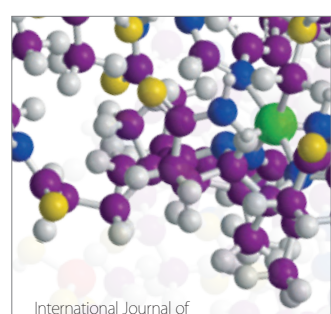

Carbohydrate Chemistry

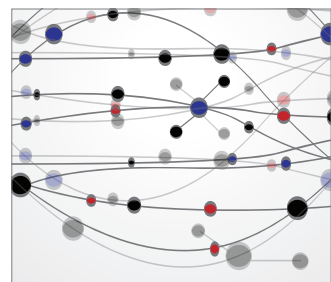

The Scientific World Journal
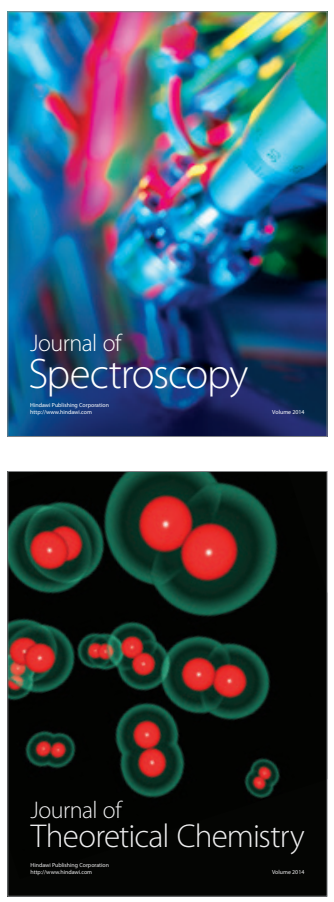
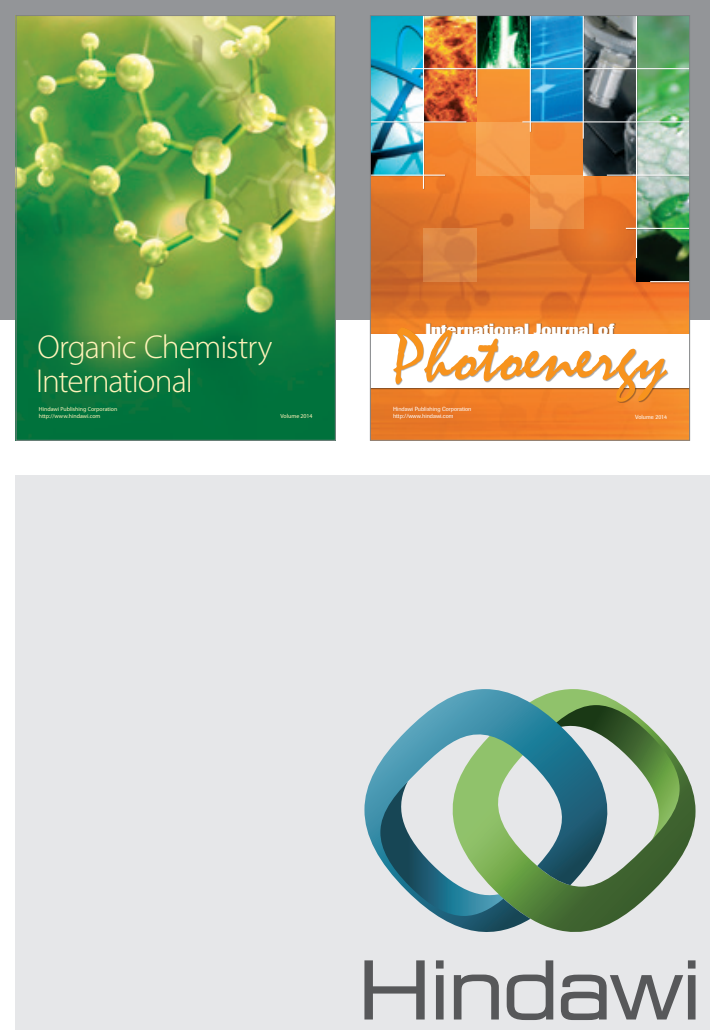

Submit your manuscripts at

http://www.hindawi.com
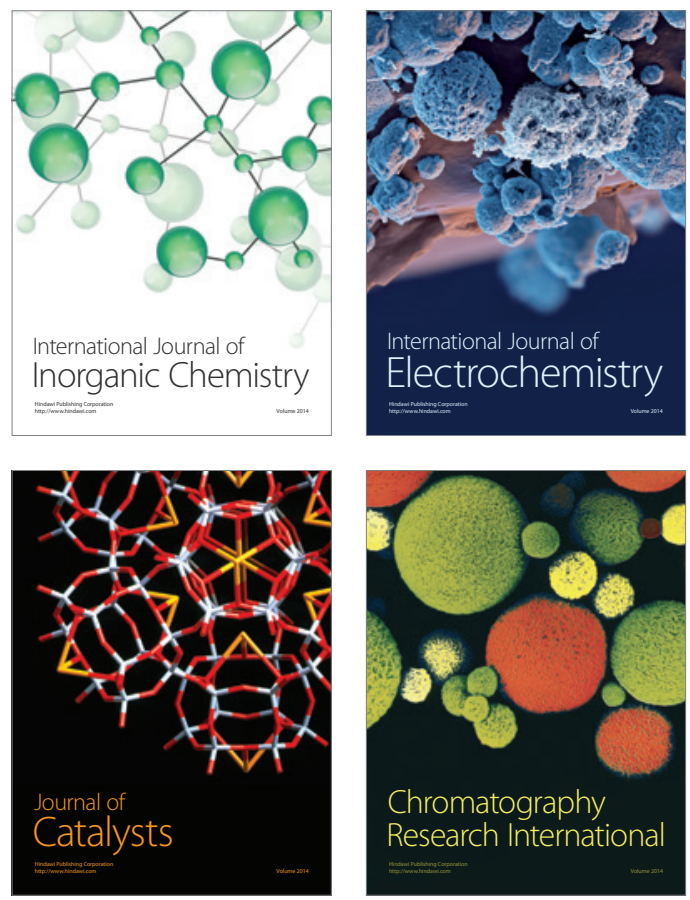
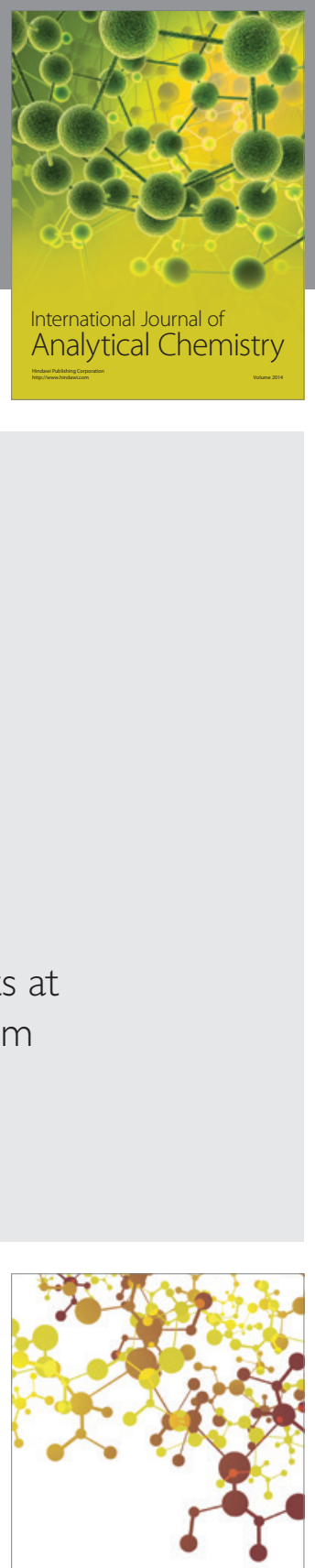

Journal of

Applied Chemistry
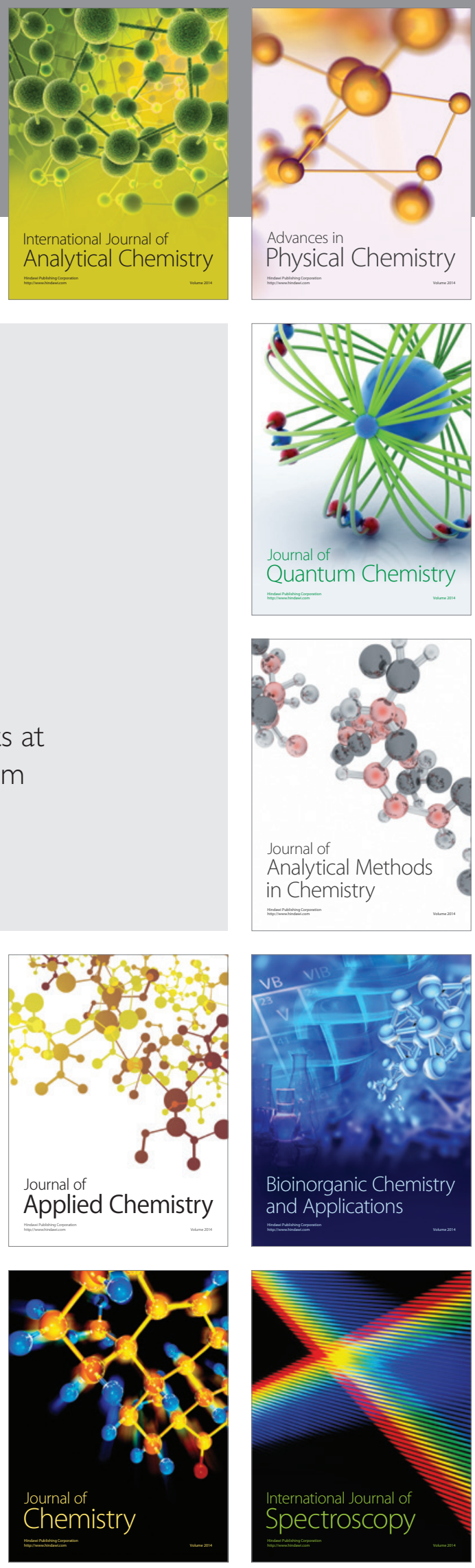